\title{
VIEWS OF YOUNG PEOPLE ON THE IMPORTANCE OF MARKETING COMMUNICATION IN TERMS OF ACCESSING EUROPEAN FUNDS
}

\author{
Mihai Orzan ${ }^{15}$ \\ Anamaria Catălina Radu ${ }^{16}$ \\ Andra Iuliana Dobrescu ${ }^{17}$ \\ Maria Cristina Mitrică $\breve{18}^{18}$
}

\begin{abstract}
With Romania's accession to the European Union, it has benefited from a number of advantages including the possibility of accessing funds. Projects financed from external funds are some of the most important instruments that are aimed at the improvement of businesses conducted in the country. In recent years, Romania has registered fairly low values in terms of the absorption of European funds. Excessive bureaucracy and how the communication process takes place have put a powerful imprint on the activities undertaken in this field. The study presented in this paper aims to identify young people's views on the importance of marketing communication in this business sector. To meet the objectives, a quantitative research was conducted on a sample of 70 respondents. The data were analyzed using the IBM SPSS Statistics 20 software.
\end{abstract}

Keywords: online marketing, European funds, marketing communication.

JEL Classification: M31

\section{The Importance of Structural Funds in Romania}

Between 2007 and 2013, structural funds in Romania were represented both via the 7 Ops which belonged to the Convergence objective, and through four operational programmes for European territorial cooperation. For each program previously mentioned, the European Commission allocated a budget based on the importance of existing fields. In terms of absorption capacity, Vitek (1999) defined it as, "extent to which a state is able to fully utilize the financial resources allocated from EU funds, effectively and efficiently". This capacity is required to make a maximum contribution to the economic and social cohesion (Bourguignon, Sundberg, 2006).

Convergence OPs existing in the period 2007 to 2013 in our country are: the Sectoral Operational Programme Human Resources Development; the Operational Programme Administrative Capacity Development; the Operational Programme Technical Assistance; the Regional Operational Programme; the Sectoral Operational Programme Environment; the Sectoral Operational Programme Increase of Economic Competitiveness; the Sectoral Operational Programme Transport.

The Operational Programme Human Resources Development (SOP HRD) specifically covers human capital development and competitiveness increase. These two objectives can be achieved by linking education and learning with the labour market, and by providing opportunities to participate in

\footnotetext{
${ }^{15}$ Bucharest University of Economic Studies, 15-17 Calea Dorobanți, sector 1, 010552, Bucharest, Romania, orzang@ase.ro

${ }^{16}$ Bucharest University of Economic Studies, 15-17 Calea Dorobanţi, sector 1, 010552, Bucharest, Romania,

${ }^{17}$ Bucharest University of Economic Studies, 15-17 Calea Dorobanți, sector 1, 010552, Bucharest, Romania,

${ }^{18}$ Bucharest University of Economic Studies, 15-17 Calea Dorobanți, sector 1, 010552, Bucharest, Romania,
} 
future on the labour market. This project comprises six priority axes which addresses both the problems encountered in the system and the individual ones at regional and national level (fonduri-EU.ro). The Operational Programme Administrative Capacity Development (OPACD) aims to improve the work at the administrative level by creating an efficient and effective system to improve the work carried out at socio-economic level. This project comprises three axes which aim to make work at government level efficient. (fonduriadministratie.ro)

The Operational Programme Technical Assistance (OPTA) aims to provide a continuous process of implementation of Structural Instruments in Romania in accordance with the existing partnership principles and rules. Potential beneficiaries of this program can apply to projects until January 2015. Its main objective is to ensure the ongoing support required in coordinating all processes that contribute to the efficient and transparent implementation and uptake of Structural Instruments in Romania (fonduri-EU.ro ).

The Regional Operational Programme - ROP seeks the economic and social development of regions existing in our country, in accordance with the needs and resources identified at their level. This program includes six priority axes that are designed to meet the overall objective of the operational programme. Axes are: supporting the sustainable development of cities - urban growth poles, improving regional and local transport infrastructure, improving social infrastructure, supporting the development of the regional and local business environment, sustainable development and promoting tourism, and providing technical assistance (fonduri-structurale.com).

The Sectoral Operational Programme Environment aims to reduce disparities between Member States of the European Union and Romania in terms of environmental infrastructure (analyzed quantitatively and qualitatively). This Operational Programme aims to improve the living standards of the population and the environment. The general objective is achieved through the six existing axes, namely: improving the quality and access to the water and wastewater infrastructure; developing sustainable waste management systems; reducing the negative environmental impacts and mitigating climate changes caused by urban heating systems; protection and improvement of biodiversity and natural heritage; reducing the risk of natural disasters (fonduri-EU.ro).

The Sectoral Operational Programme Increase of Economic Competitiveness (SOP IEC) aims to increase the productivity of enterprises in Romania. Achieving this goal is accomplished through the five related axes, namely: creating an innovative and eco-efficient production system; research, technological development and innovation for competitiveness; research and information technology for the public and private sectors: increasing energy efficiency and the security of supply in the context of fighting climate change, which has the objective of obtaining efficient and sustainable energy and providing technical assistance (amposcce.minind.ro).

The Sectoral Operational Programme Transport (SOP-T) aims to promote a sustainable transport system in Romania characterized by safety, speed and efficiency. At the level of this programme, there are four priority axes, namely: the modernization and development of trans-European transport priority axes in order to develop a sustainable transport system and to integrate it with EU transport networks; the modernization and development of the national transport infrastructure in order to develop a sustainable national transport system; the modernization of the transport sector to improve environmental protection, human health and passenger safety, and providing technical assistance (ampost.ro).

Considering all the above, we believe it is necessary to conduct both quantitative and qualitative research to illustrate the perception of the potential beneficiaries of projects accessed from European funds.

\section{Research Methodology}


The field of accessing European funds is dynamic, constantly changing depending on the activity conducted at the level of the Member States. Therefore, it requires a continuous analysis to highlight how these changes influence the absorption of EU funds at national level. Marketing can be successfully applied in the field, increasing the absorption of European funds. In this paper we conducted a quantitative study on a sample of 70 respondents, aged 18 to 25, with knowledge in both marketing and accessing European funds. The research was carried out in Bucharest between February 3, 2014 and February 17, 2014. The data were analyzed using the IBM SPSS Statistics 20 software.

\subsection{Analysis of Results}

Regarding the importance of marketing communication in terms of accessing European funds, we noted that, overall, respondents believe that foreign funded projects contribute significantly to the economic development of Romania, as evidenced also by the average recorded (8.29). Over half of those surveyed believe that accessing EU funded projects contributes to a great or very great extent to the country's economic growth, thereby being ranked with 9 or 10.

Figure 1 - Extent to which EU funded projects contribute to national economic growth

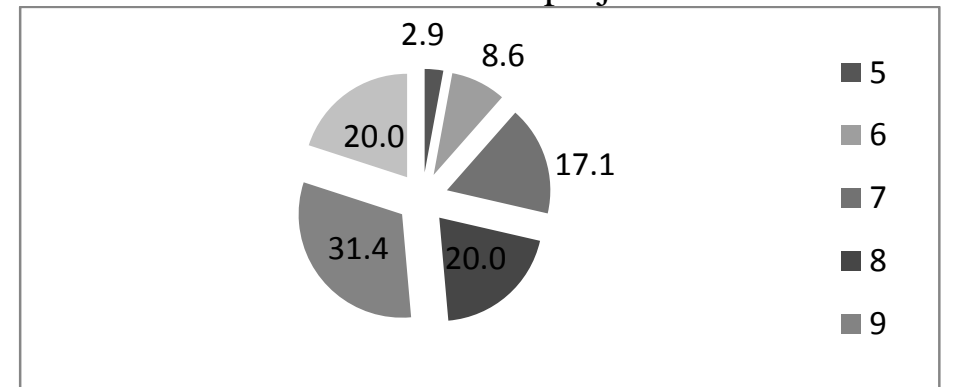

Figure 1 - Extent to which EU funded projects contribute to national economic growth Source: statistical survey conducted by the authors

Most respondents believe that tourism is the most representative field that could be successfully exploited when taking into account EU funded projects. 1 of 3 participants argue that education captures excellent opportunities that can be exploited through these projects.

$11.4 \%$ of all respondents believe that EU funds should be focused mainly on infrastructure/transport, while only $8.6 \%$ said that they could be beneficial to other fields than those mentioned above. 


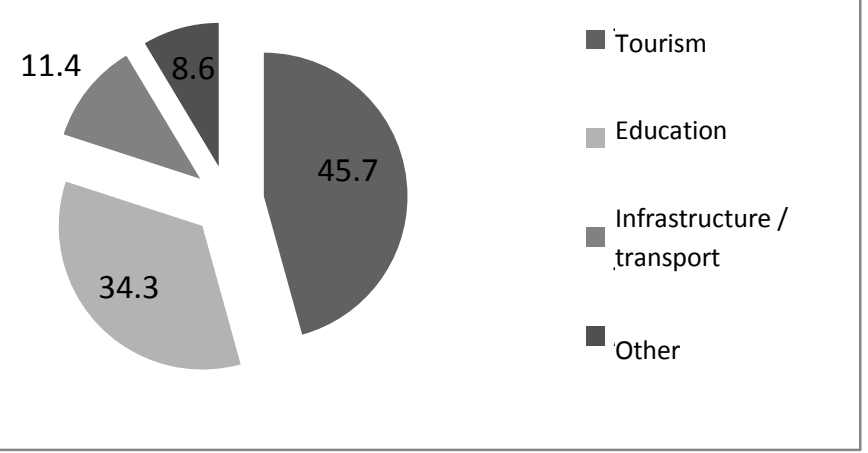

Figure 2 - Fields which should be aimed by European funds in Romania Source: statistical survey conducted by the authors

The vast majority of respondents $(85.7 \%)$ observed that excessive bureaucracy is the main barrier that prompted a low degree of absorption of EU funds at national level. Also, 62.9\% of participants identified another important barrier that prevents the access to external funds, namely: the lack of information on how these funds can be accessed. The lack of online tools to facilitate the contact between the parties is an important barrier for $51.4 \%$ of respondents, followed by lack of project models to support the beneficiaries while drafting (37.1\%). Only $14.3 \%$ of respondents mentioned other barriers than those stated above.

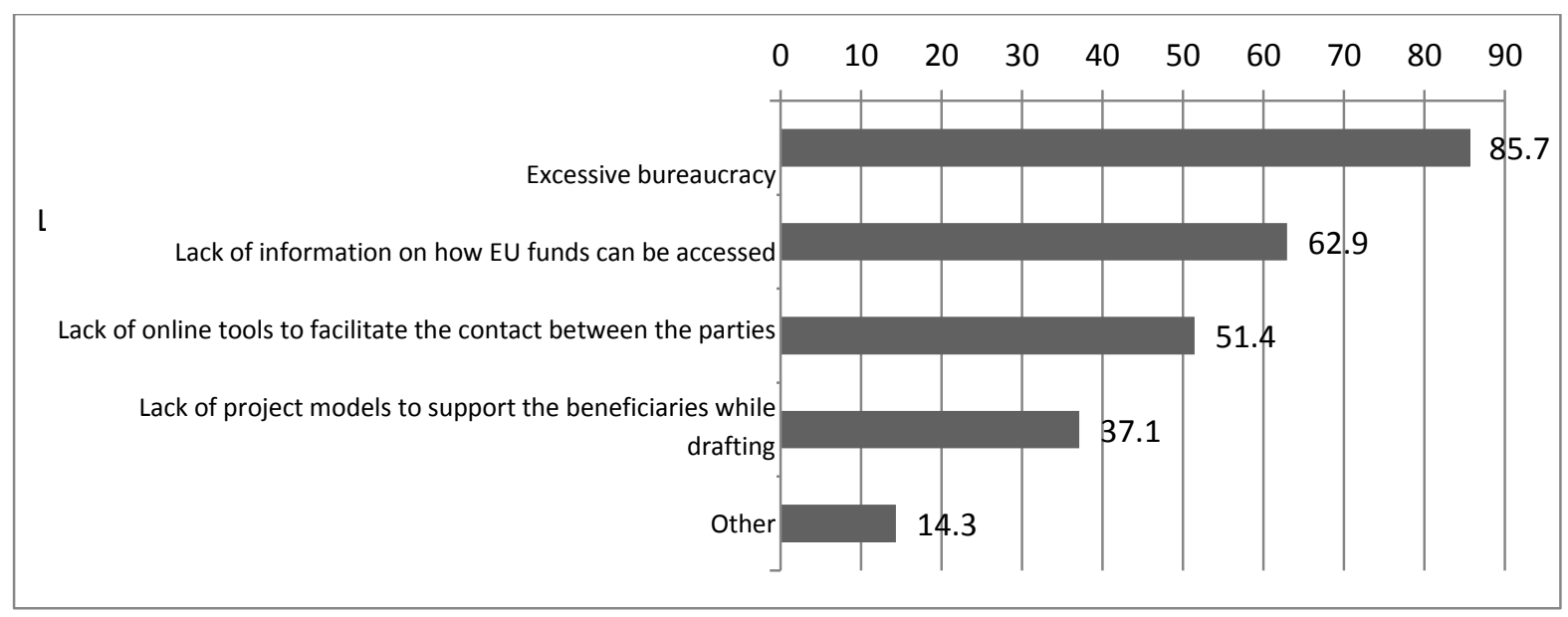

Figure 3 - The main barriers that prevent the absorption of EU funds at national level Source: statistical survey conducted by the authors

The application of marketing in terms of accessing European funds generated for most respondents a positive opinion, in that $68.6 \%$ of respondents consider that carrying out specific activities to this field in terms of accessing external funds will contribute to a great / very great extent to the increase of their absorption. $22.9 \%$ of respondents had a neutral opinion regarding the problem studied, while 3 out of 10 respondents said that carrying out marketing specific activities in terms of accessing European funds will contribute little or very little to improving the absorption of EU funds. 

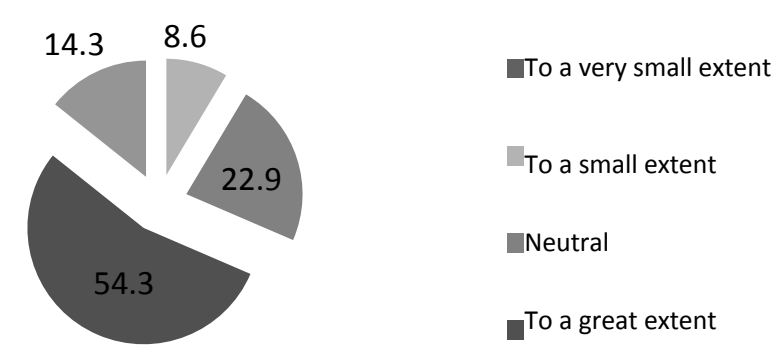

Figure 4 - Extent to which the marketing activity would improve the activity carried out in terms of accessing European funds

Source: statistical survey conducted by the authors

Most respondents believe that the existing communication process in terms of accessing European funds is efficient, this conclusion also being supported by the average recorded (6.74).

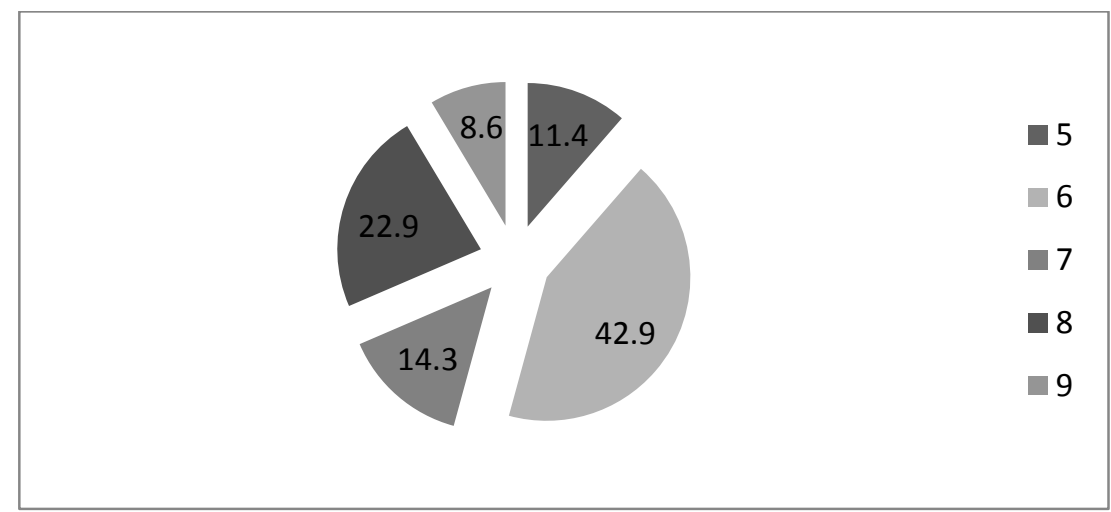

Figure 5 - The efficiency of the existing communication process in terms of accessing European funds Source: statistical survey conducted by the authors

$68.6 \%$ of the reviewed persons mentioned that the way to provide information on accessing European funds should be achieved both through traditional media and online. $17.1 \%$ of all respondents want this information to be transmitted exclusively online, while $14.3 \%$ believe that they should be sent only through traditional media.

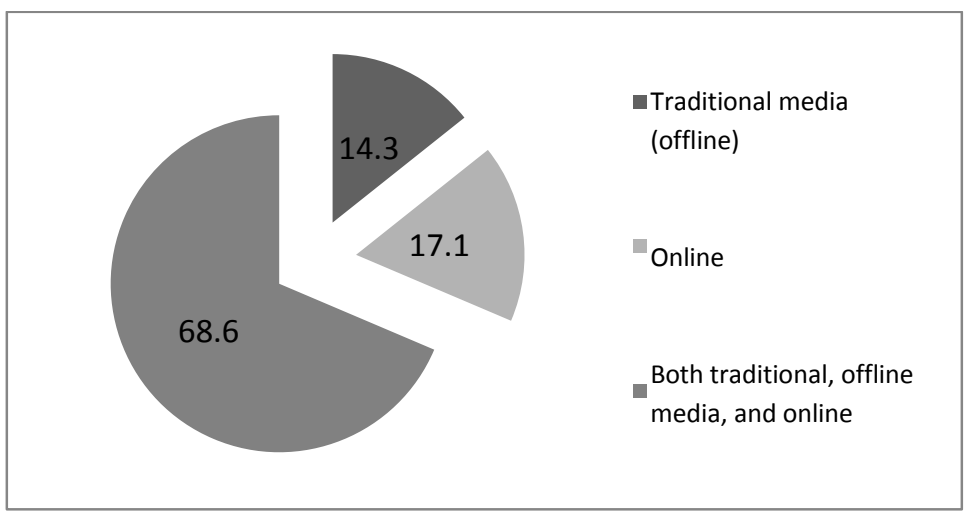

Figure 6 - Communication media which should be used in terms of accessing European funds Source: statistical survey conducted by the authors 
Over $80 \%$ of those interviewed believe that websites are important/very important in online communication in terms of accessing European funds, followed by forums (over $60 \%$ of study participants) and blogs (more than 30\%). Social networks have been classified as unimportant or not important for $57.1 \%$ of respondents, while other marketing tools mentioned have obtained less importance compared to the aforesaid.

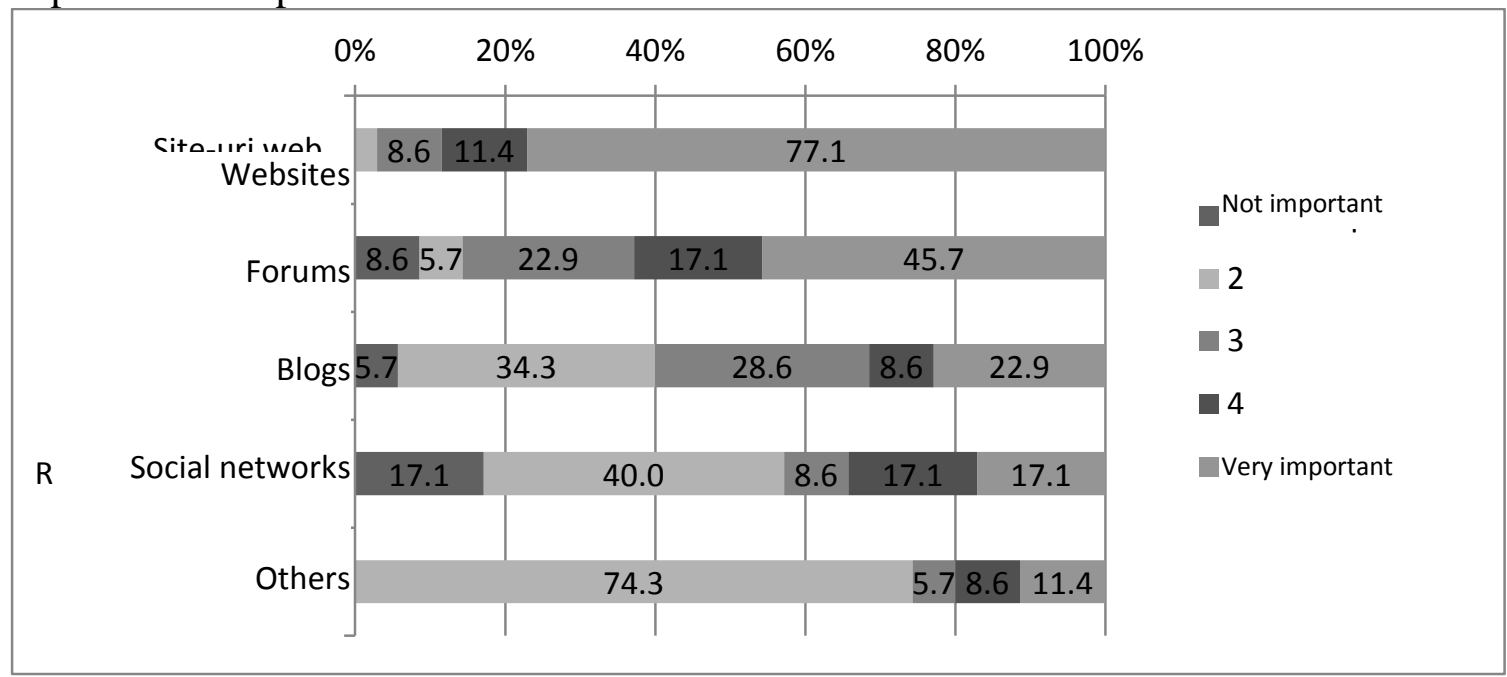

Figure 7 - The importance of online marketing tools in terms of accessing European funds Source: statistical survey conducted by the authors

Communication in terms of accessing European funds could be improved by creating an online platform through which to achieve the exchange of best practices (68.6\% of all respondents). Over half of those surveyed believe that the implementation of a call center for the quick resolution of problems encountered would improve communication of parties involved. In addition, the creation of forums specifically dedicated to people working in this field would facilitate the contact between persons who have completed at least one project and potential beneficiaries. 1 in 4 respondents believe that communication in terms of accessing European funds can be greatly improved by conducting workshops, while only $14.3 \%$ of respondents mentioned other ways to improve communication in this field.

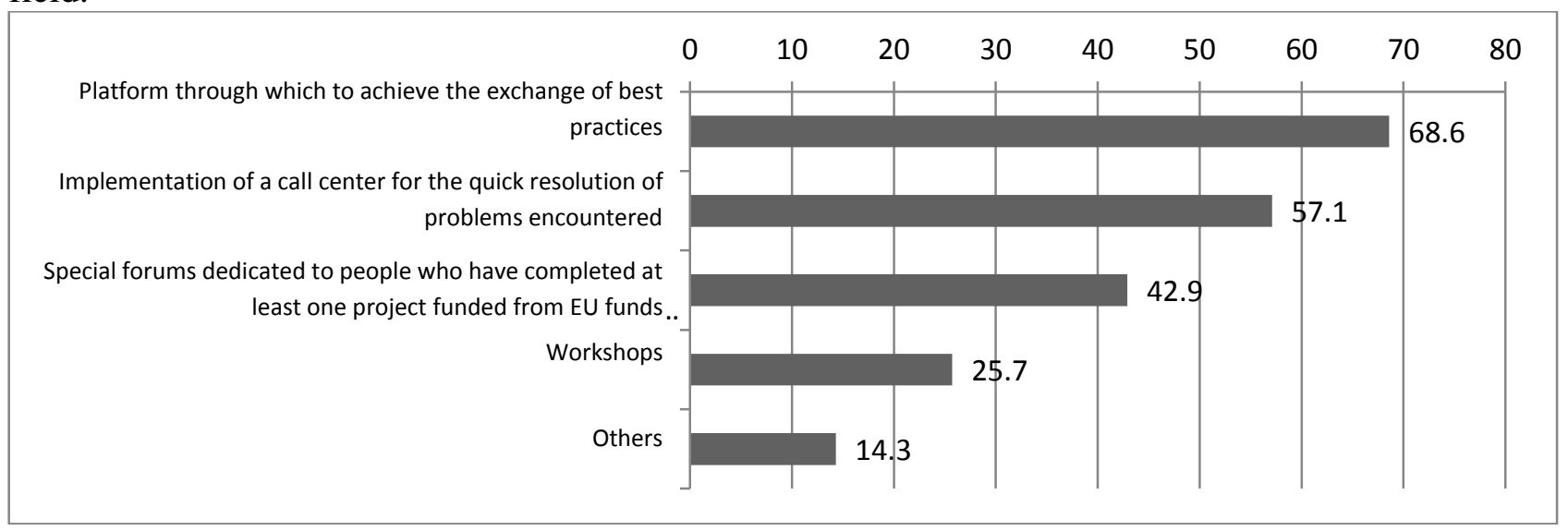

Figure 8 - Main methods that would improve the existing communication process in terms of accessing European funds

Source: statistical survey conducted by the authors 


\section{Research limits}

Identifying young people's opinions on the importance of marketing communication in terms of accessing European funds is very important, it being aimed at highlighting how future marketing specialists perceive the work carried out in this sector. Although this study provided us with relevant information relating to the matter under review, a thorough analysis is required among current beneficiaries to highlight how the marketing activity can be used to improve the processes running at that level. Thus, qualitative studies can be carried out illustrating the views of both the beneficiaries and the specialists. To get a clearer picture of the problem studied, quantitative researches can be conducted to highlight punctually the steps to be taken to improve the overall communication process. Another limitation identified in this study refers to the number of respondents who participated in this research. Since their number is small, we cannot extrapolate the results to the entire population studied. The study considered only certain variables that have the ability to reflect the views of young people on the importance of marketing communication in terms of accessing European funds. Therefore, further research will need to consider a wider range of variables that have the ability to better explain the subject analyzed.

\section{Conclusions}

Marketing communication plays an important role across multiple industries, including the one related to accessing European funds. Improving the communication within this sector automatically leads to increased efficiency of work and the improvement of the contact between the parties. In this field, marketing communication can take place both in traditionally and online, through specific marketing tools. Combining the two means of communication facilitates the exchange of information between transmitter and receiver allowing a permanent feedback from him. As previously observed in the study, online communication is designed to support traditional communication by giving users a range of applications and tools to enhance information exchange.

Currently, the most widely used online communication tool in terms of accessing European funds is the website. Through it, the following occur: transmitting information about projects completed or that are currently underway; providing information necessary for accessing European funds and communication with potential beneficiaries. Considering all the above, we believe that the online environment can improve the existing communication process in terms of accessing European funds through the creation of applications that facilitate the transmission of information and documents. In addition, online platforms can be constructed in which the beneficiaries may be able to discuss both with people specialized in this field and others who have previously accessed European funds.

In conclusion, we believe that the harmonious blending of the two communication media in this field of activity can lead to the increased absorption of EU funds in the coming years.

\section{Acknowledgement}

This work was cofinanced from the European Social Fund through Sectoral Operational Programme Human Resources Development 2007-2013, project number POSDRU/159/1.5/S/134197 „Performance and excellence in doctoral and postdoctoral research in Romanian economics science domain" This work was cofinanced from the European Social Fund through Sectoral Operational Programme Human Resources Development 2007-2013, project number POSDRU/159/1.5/S/142115 „Performance and excellence in doctoral and postdoctoral research in Romanian economics science domain" 


\section{References}

1. Bourguignon F., Sundberg M., 2006. Absorptive capacity and achieving the MDG's UNU WIDER, Research paper no. 47.

2. Vitek L., 1999. Welfare state development during the transition: the Czech Republic case, 1999 in Caddy Joanne, Jabes J., Improving the relations between the administration and the public, NISPAcee Publishing House, Slovakia.

3. http://www.fonduri-EU.ro, accessed on 12.08.2014.

4. http://www.fonduriadministratie.ro/ro/, accessed on 14.08.2014.

5. http://www.fonduri-structurale.ro/Detaliu.aspx?t=capacitate, accessed on 16.08.2014.

6. amposcce.minind.ro, accessed on 10.08.2014.

7. http://www.ampost.ro/, accessed on 22.08.2014. 